as follows. In surveying the physical landscape we have discovered certain facts which we cannot fit into the same plan as the more familiar ones: every attempt to co-ordinate them involves us in absurdity. There are two ways out of the difficulty. The first, which appears to be the only one attempted-or, at any rate, popularised-so far is to assume that the landscape is absurd, and that instead of marvelling that we cannot make a rational conception of it, we should rather pity our former inability to see that absurdity is the essence of Nature. The second way, which at least seems worth trying, is to change our point of view until the spectacle again becomes coherent. To do this is not easy : it is much pleasanter to lie in a bed of chaos and smile at our folly in thinking reason worth while. But the time may come when we shall regret such a choice.

It is a question for the specialist now, but in a few decades it will be a matter of universal importance; for the abstract thought of one generation, operating unperceived by the majority, directs the practical activities of the next. It is not merely scientifically indefensible, it is socially tragic when a tremendous forward leap in human thought, about which the public is curious to a degree never before witnessed, is represented as a negation, by an unintelligible formula, of all that has been proved trustworthy in the past; when a man like Sir Arthur Eddington, who is responsible for the most valiant attempt yet made to form a positive unity of the new ideas, can for public instruction give as a summary of the whole situation the vague and inaccurate phrase, "Something unknown is doing we don't know what"; when Sir James Jeans can so far forget his own admirable work as to write, "Heisenberg now makes it appear that Nature abhors accuracy and precision above all things"; and when the only means the truthseeker has of detecting the falsity of these statements-namely, the exercise of the reason with which he is naturally endowed-is made impotent by the suggestion that mathematics, which he has no time to learn, has discovered how to prove the illogical. There is here a situation far more serious in the long run than many of the problems which agitate public life to-day.

Freedom of thought may be attacked in two ways. Many recently have been moved to protest against the use of external force for this purpose. But, regrettable as such control is, it cannot by its very nature constitute a real limitation. Stone walls do not a prison make, and history has shown that the blood of the martyrs is the seed of the Church. Infinitely more dangerous is the menace to thought from thought itself. When, in the name of science, criticism is not chained but drugged, and unreason, in robes not its own, receives the homage meant for reason, thought is enslaved indeed. Those who are wise enough to see how the social life of a people is related to its mental state will scarcely contemplate the future with equanimity.

\title{
Diet and Dental Disease in Man
}

TT is now well established that there is an 1 intimate relationship between the structure of the teeth in animals and the composition of their food supply, as well as between the latter and certain forms of dental disease. The work of Mrs. Mellanby on these problems has already been referred to in these columns (NATURE, 125, 604 ; 1930. 127, 977 ; 1931). The results of these researches led naturally to an investigation of the problem of dental caries in human beings, along original lines, with the view of determining whether a similar relationship between diet and structure and disease held here also. An interim report of a clinical trial by the Committee upon Dental Disease was issued in 1931 (Nature, 129,83 ; 1932) and is now followed by the full account of Mrs. Mellanby's experiments upon the effect of diet on dental structure and disease in man*.

An account is given first of normal and abnormal development and structure of the teeth: by normal is meant the perfect structure which can be obtained in animals receiving vitamin $\mathrm{D}$ and a sufficiency of calcium and phosphorus. The normal tooth is creamy white, smooth and shiny in

\footnotetext{
* Medical Research Council. Special Report Series, No. 191 : Diet and the Teeth ; an Experimental Study. Part 3 : The Effect of Diet on Dental Structure and Disease in Man. By May Mellanby. Pp. 180. (London: H.M. Stationery Office, 1934.) 58. net.
}

appearance, the enamel is relatively thick and regular in outline, with a more or less regular, systematic arrangement of the prisms and comparatively little pigmentation. The dentine is relatively thick and shows no poorly calcified areas (or interglobular spaces). Such spaces are rare in animals living under natural conditions, but in civilised man, who lives under artificial conditions, their presence is the rule rather than the exception. Teeth can be graded according to the surface character of the enamel, even while still in the mouth: good correlation was found between surface texture and minute structure in the shed or extracted teeth submitted to microscopical examination, so that it is possible to infer the histological structure of teeth while still in the mouth.

In a collection of more than 2,000 shed and extracted teeth, it was found that, whether assessed by surface or histological examination, the majority of the deciduous teeth were defective (hypoplastic) in structure, the incisors being the best and the second molars the worst formed. Teeth collected from private sources were better calcified than those from public elementary school children. The majority of the permanent teeth were also hypoplastic. The teeth of two groups of children were also examined, the first in a hospital 
for surgical tuberculosis (1,684 deciduous and 1,453 permanent teeth) and the other in cottage homes $(12,807$ deciduous and 14,078 permanent teeth). 21 per cent of the deciduous teeth of the latter group and 7 per cent of those of the former had no defects; 32 per cent of the former's but only 5 per cent of the latter's were very hypoplastic. As regards the permanent teeth, 1 per cent were normal in the hospital children and 24 per cent in the cottage homes children, 43 and 8 per cent being very hypoplastic respectively. Histological examination indicated that in the majority of deciduous teeth the part formed before birth was well calcified, the defects beginning to form, however, soon after birth.

As regards caries, of which three degrees were arbitrarily recognised, it was found that 27 per cent of the deciduous teeth of British children were free from the disease, while 42 per cent were very carious. 67 per cent of the incisors but only 4 per cent of the second molars were caries-free; 10 per cent of the incisors and 63 per cent of the second molars were severely affected. The teeth collected from private sources were less carious than those of the children from public elementary schools. Caries was also more prevalent in the children in hospital than in those in the cottage homes : 47 per cent of the teeth in the former group and 73.5 per cent of those in the latter were free from the disease. Caries was extensive in 22 per cent and in 7 per cent respectively in the two groups. 68 per cent and 83 per cent of the permanent teeth were healthy. The incisors and canines were the least and the first molars the most affected.

The data given above suggest that there is a close relationship between the structure of the teeth and their liability to caries. It was found on analysing the figures more closely that, of the deciduous teeth diagnosed as normal by surface appearance or by the histological structure of the enamel or dentine, 77-83 per cent were free from caries, whilst $2-10.5$ per cent were severely affected. On the other hand, of those diagnosed as very hypoplastic, only 7-9 per cent were free from caries, 60.5-73 per cent being severely affected. The same general association holds also in the case of the teeth examined in the mouth, including the permanent teeth. Mrs. Mellanby concludes : "It can therefore be stated as a general hypothesis that there is a close direct association between structure and caries."

Only in 11.2 per cent of the deciduous teeth was no direct association found, $5 \cdot 1$ per cent being too carious for the structure and $6 \cdot 1$ per cent less carious than might have been expected from the structure. Examination of the sections for the presence of secondary dentine and its structure when present showed that teeth of poor structure yet free from caries had well calcified dentine, whilst the latter was usually imperfectly formed when caries appeared in a tooth originally wellformed. In other words, the defensive reactions of the teeth after eruption play a part in the association between structure and caries. Only about 2 per cent of the 1,500 teeth examined were gross exceptions to the two hypotheses of direct association between structure and incidence of caries and that there may be a change in the resistance of the teeth after eruption which is indicated by the character of the secondary dentine.

The next step was the experimental confirmation of the relationship between diet and structure and so between diet and caries in human beings. Four successive investigations were made in a Sheffield Hospital for surgical tuberculosis and afterwards two concurrent tests on children in the Birmingham Cottage Homes, one lasting for two years and the other for a year and a half. The ordinary diets given the children were those commonly considered adequate in all respects : the modifications made were additions of oatmeal, olive oil, cod liver oil or radiostol (irradiated ergosterol), and milk, butter and eggs, or removal of oatmeal and other cereals. The energy value, fat, protein and carbohydrate content, as well as the amounts of calcium and phosphorus present, were kept as constant as possible in the different diets; on the cereal-free diet the carbohydrate was reduced and the fat proportionately increased. In the Sheffield investigations, considering only the children less than six years old (as the average age in the earlier investigations was about eight years), it was found that the average number of teeth per child showing initiation or spread of caries was reduced from $5 \cdot 0$ on the diet containing no extra vitamins $\mathrm{A}$ and $\mathrm{D}$, but with increased oatmeal, to $0 \cdot 37$ on the cerealfree diet with addition of cod liver oil and radiostol solution daily. The average number of teeth per child in which caries showed hardening was increased from $0 \cdot 2$ to $4 \cdot 7$. The Birmingham results bore out those previously obtained in Sheffield and showed that vitamin $\mathrm{D}$ is an important factor in checking the initiation of fresh caries, diminishing the spread of old caries and arresting the infective process in many carious teeth.

Following the discussion of the experimental evidence in favour of the thesis that diet and dental disease are intimately related through the variations in structure of the teeth which can be produced by changing the diet, the report considers the racial distribution of caries, since the thesis ought to be capable of explaining the relative immunity or susceptibility of races and communities in various parts of the world. A review of the available evidence suggests that the main conditions responsible for immunity from dental decay are prolonged breast-feeding with a supplementary diet often for three or even six years and a high intake of vitamin $D$ (or exposure of the body to the sun) together with a sufficiency of calcium and phosphorus. A high carbohydrate diet (cereals or potatoes) is compatible with good teeth provided the supply of vitamin $\mathrm{D}$, calcium and phosphorus is also sufficiently great. Caries is especially rampant where cereals form a large part of the diet, breast-feeding is short, the intake of milk, eggs and animal fats is small and 
sunshine is negligible or rendered ineffective by clothing.

It has thus been shown that perfectly calcified and regularly arranged teeth can be produced by including in the maternal diet during pregnancy and lactation, and in the diet of the offspring at the time of dental development, substances containing much vitamin $\mathrm{D}$, calcium and phosphorus, such as milk, eggs, fish and animal fats, and that cereals, especially those rich in embryo such as oatmeal, tend to produce hypoplastic teeth and call for a correspondingly larger supply of calcifying foods for good development. It has further been established that the teeth of the majority of children in Great Britain are imperfect in structure: that dental caries is more likely to attack such teeth than perfect teeth with normal enamel and dentine and a smooth surface ; that the resistance to caries can be increased independently of the original structure by giving a diet containing much vitamin $\mathrm{D}$, calcium and phosphorus or decreased by a diet rich in cereals. If these general principles of feeding were widely adopted, there is little doubt that dental caries (and also pyorrhœa, to which a deficient intake of vitamin A predisposes) "will cease to be the scourge they are at the present time". It may finally be pointed out that none of these conclusions conflicts with the generally accepted idea that the exciting cause of caries is the growth of micro-organisms in the mouth: the novelty is the proof that the tooth can resist the onslaught of the microbes by the absorption and assimilation into the body tissues of certain specific dietary factors.

\section{Obituary}

\section{Mr. E. M. Eden}

$\mathrm{E}$ DGAR MARK EDEN died on February 10 at the age of sixty years. He was the eldest son of William Eden, an artist, and was educated at University College, London. After a period with Messrs. Willans and Robinson, ended by ill-health from which he was never wholly free, he became a demonstrator at University College under Prof. Hudson Beare, by whom he was greatly influenced. In 1907 he became lecturer at Armstrong College, where he remained until his life-work began in 1915.

The National Physical Laboratory had undertaken the testing of all gauges for the manufacture of munitions. The old methods were inadequate to deal with the immense number of gauges, and especially screw gauges; entirely new and simpler methods were necessary. Here Eden's genius found its appropriate field. Many others shared in the work; but they would agree that every method finally adopted owed something to his inspiration, and that many of the most important owed everything. The simple machines that he devised for the most intricate measurements did much more than solve an urgent war problem. They enabled British manufacturers to test their own products and to raise appreciably their standard of accuracy. In the list of those who have led the post-War reconstruction of our industries Eden's name should stand high.

In 1919 Eden joined the original staff of the newly founded Research Laboratories of the General Electric Co., Ltd., as head of the workshops. His work now covered a much wider range, but knowledge of it was necessarily confined to a narrower circle. Discerning visitors to the Physical Society's Exhibition will have realised that its quality remained unchanged; but only his colleagues know how much of any success they may have achieved is due to it.

It is impossible to describe examples of his work in a few words; reference must be made to published accounts, for example, in Rolt's "Gauges and Fine Measurements" and in the Journal of Scientific Instruments (May 1922, and vol. 2, p. 119). All his work had a common feature, an economy of means and of material characteristic alike of the best science and the best art. Among modern Englishmen only Rayleigh and Horace Darwin can be compared with him in this matter. Like them he always went straight to fundamentals; he would not even take a hackneyed formula from a textbook; he always worked it out for himself. The colleague who brought him a sketch was often disconcerted to find the final apparatus shorn of all his cherished ingenuities; but it always worked at a first trial, and achieved exactly what was required of it, neither more nor less.

The same hatred of elaboration and ostentation inspired Eden's private life. He loved wild flowers, but not the formal garden ; the elegance of Mozart, but not the grandeur of heavy orchestration. It made him a true peace-lover; only his duty to his young family persuaded him, after a bitter struggle, to take even an indirect part in hated strife. Yet he was no shrill pacifist; quarrels vanished like smoke before his genial smile and kindly, but caustic, humour. He was a perfect host; and his accounts of workshop doings at staff meetings were so entertaining that they became recognised as among the Laboratory treats. We are all much poorer for his loss, though the world at large may never know it. He leaves a widow and four sons.

\section{Dr. H. M. CADell}

The sudden death of Dr. H. M. Cadell on April 10 at the age of seventy-three years has deprived Edinburgh and its neighbourhood of a distinguished scientific worker and of one who played a conspicuous and most useful part in the life of the community. Born in 1860, he was educated at the University of Edinburgh and at 